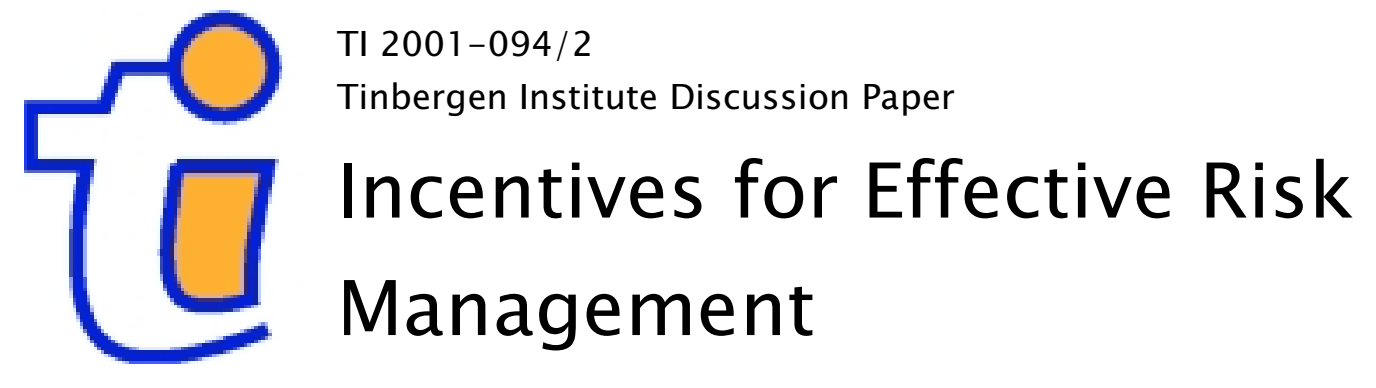

\author{
Jón Daníelsson ${ }^{1}$ \\ Bjørn N. Jorgensen ${ }^{2}$ \\ Casper G. de Vries 3
}

' London School of Economics,

2 Harvard Business School,

${ }^{3}$ General Economics, Faculty of Economics, Erasmus University Rotterdam, and Tinbergen Institute 
Tinbergen Institute

The Tinbergen Institute is the institute for economic research of the Erasmus Universiteit Rotterdam, Universiteit van Amsterdam and

Vrije Universiteit Amsterdam.

Tinbergen I nstitute Amsterdam

Keizersgracht 482

1017 EG Amsterdam

The Netherlands

Tel.: +31.(0)20.5513500

Fax: $\quad+31 .(0) 20.5513555$

Tinbergen Institute Rotterdam

Burg. Oudlaan 50

3062 PA Rotterdam

The Netherlands

Tel.: $\quad+31 .(0) 10.4088900$

Fax: $\quad+31 .(0) 10.4089031$

Most TI discussion papers can be downloaded at

http://www.tinbergen.nl 


\title{
Incentives for Effective Risk Management *
}

\author{
Jón Daníelsson \\ Bjørn N. Jorgensen \\ London School of Economics Harvard Business School \\ Casper G. de Vries \\ Erasmus University Rotterdam, Tinbergen Institute, and NIAS
}

September 2001

\begin{abstract}
Under the new Capital Accord banks can choose between different type of risk management systems. Using a stylized model of risk management systems which differ in quality and by modelling the relationship between the bank board and the risk manager, we consider the incentives for the adoption of a particular system. We show that in some cases banks may adversely adopt an unsophisticated risk management system in order to evade regulation.
\end{abstract}

JEL G18

\footnotetext{
${ }^{*}$ We are grateful for the detailed and helpful comments of a anonymous referee, to Sudipto Bhattacharya, Elizabeth Keating, Richard Payne, Jean-Charles Rochet, and seminar participants at the University of Bern, the University of Rome Conference 'Statistical and Computational Problems in Risk Management: VaR and Beyond VaR', the Cardiff meeting of the European Monetary Forum for helpful suggestions, and the editor for his support. We wish to thank the Erasmus University Trust fund for a research grant, and the NIAS for its hospitality. Updated versions of the paper may be downloaded from www.RiskResearch.org. Corresponding author Casper G. de Vries, cdevries@few.eur.nl.
} 


\section{Introduction}

Regulators already require that banks measure market risk with statistical models, specifically Value-at-Risk (VaR) (see the Basel Committee on Banking Supervision, 1996). Under the latest Basel-II proposals, the same general methodology can be applied to measuring credit, operational, and liquidity risk. In other words, statistical risk modelling (termed Internal Rating Based or IRB) will become the linchpin upon which the stability of the financial system rests. ${ }^{1}$ While the IRB approach has been well studied, one aspect has received little attention: the participants' preference for heterogeneity in the risk modelling process, in particular incentives the key parties have for accurately measuring risk, and the contractual relationship that binds the risk manager, the bank owner, and the supervisor. Moreover, banks may opt out of the IRB approach and use the BIS standardized approach. Our aim is to explicitly address how a financial institution choices the quality of its risk management system.

The environment is a classical principal-agent relationship between a bank's board of directors (principal) and a risk manager (agent). The setting is complicated by the presence of external supervision which affects both the agent and the principal. It is costly for the principal to measure risk, and costly for the agent to reduce risk. This gives rise to an optimal intensity of risk measurement and management. By introducing supervision, and hence disclosure, into a previous unregulated setting, we find that supervision directly affects the level of risk management. Furthermore, we demonstrate that the new accord has real effects, it is procyclical, and with appropriate regulatory design, volatility can be reduced. In setting up the model we address several issues. First, problems in specifying the regulators' preferences. Second, the reasoning for the choice of IRB and the quality level of risk management. Third, the information asymmetry between the bank and the supervisor with special reference to the fact that most banks are considerably over capitalized. Finally,the impact of regulation on bank behavior .

The supervisors receive a mandate from the government to regulate the financial industry, however in general their objectives are hard to ascertain. Regulators have been reluctant to disclose the underlying reasoning for choosing a particular regulatory regime, beyond the most general statements. For example, the General Manager of the BIS has recently conjectured (Crock-

\footnotetext{
${ }^{1}$ The IRB methodology has received widespread criticism witness the comments currently at www.bis.org/bcbs/cacomments.htm. These criticisms range from individual banks commenting on a particular aspect of the 2001 Basel-II proposals, to academics criticizing the whole approach.
} 
ett, 2000) that the key aim of financial regulation is to reduce economic costs due to financial instability. In general, the consensus seems to be that is the ultimate objective of financial regulation is to reduce systemic risk. This however is not very useful when modelling regulatory preferences, since no single definition of systemic crisis is available, (see the survey by De Bandt and Hartmann, 2000). Moreover, a translation from systemic risk tolerance to the risk tolerance by the regulator imposed on individual banks as a consequence of its systemic risk tolerance is simply not available. Therefore, in the current paper we take a positive approach and simply investigate different risk levels permitted by the regulator and the consequences for the bank. ${ }^{2}$

The strategic choice of the quality of the risk management system is the focus of this paper. It is clear that the use of internal models is preferred by both the most important supervisors and the largest banks. It is equally clear that smaller institutions and smaller countries are more skeptical of the IRB approach. The supervisory reason for preferring internal models seems to be that this may reduce regulatory arbitrage, and that the fact that banks use internal models, may give regulators better insights into the internal operations of a bank. Furthermore, Federal Reserve Bank (FRB) Governor Meyer (2000) states that internal models may in the future have a dual use for both supervisory and internal use within a financial institution where the internal model becomes a prominent part of the supervisory process. ${ }^{3}$ This is in contrast to the current regime where the regulators mostly limit themselves to observing the outcomes of internal model, and auditing the modelling process. The largest banks prefer capital determined by IRB for two major reasons: First, their capital charge will probably decrease under Basel-II and IRB. Second, it gives them a strong competitive advantage over less sophisticated institutions. Even though the largest banks prefer that capital be model determined, it also carries with it potential costs. Having regulatory supervision supervision of its risk management process may be viewed by a bank as a competitive disadvantage. Not only may it be forced to measure risk differently than it otherwise would, but the implied changes to its operations may not be preferable. As a result, banks have incentives

\footnotetext{
${ }^{2}$ Whether the regulatory measures are optimal from the societies point of view of containing systemic risk is outside the scope of the present paper.

${ }^{3}$ FRB Governor Laurence H. Meyer (2000) states:

"We should all be aware that additional public disclosure is not a free good, especially if it works. Banks will find that additional market discipline constrains their options, and supervisors will be concerned about creditors' response to bad news."
} 
to game the regulatory risk management process even if it may not affect its overall capital, and may adversely adopt a low quality system due to the very fact that they are being supervised. ${ }^{4}$ Thus the interesting question pertains to the underlying reason why internal models were promoted in the first place, and in the end one may see that several institutions opt for the standardized approach when reporting to supervisors.

We specifically consider a setting where the regulators directly observe and influence the internal risk management process in a bank, and find that this has the potential for lowering the quality of the risk management. In our Proposition 2 we argue that in the absence of regulation it is in the bank's best interests to install a high quality internal risk management system. However, subsequent to be regulated, we find in Proposition 3 that the bank might actually prefer less internal risk control activity. In other words, regulation has the potential to decrease risk control. Since, given the current regulatory regime, banks internal models are used to calculate regulatory risk capital, regulation may increase instability. Perhaps this result explains the anecdotal evidence that some banks employ dual risk management systems, an elaborate system for internal control, and a scaled-down version for reporting purposes.

\section{The Principal-Agent Relationships}

A financial institution consists of multiple interested parties each with their own preferences and agenda. For example, traders are much more risk seeking than the owners of a bank, and left uncontrolled would lead to unacceptable levels of risk taking. A bank's board of directors, or board in short, therefore specifies acceptable risk levels for each unit within the organization. The monitoring of these risk levels are left to a separate entity, the risk manager, whose function it is to measure risk and enforce risk limits set by the board. As such risk management is a cost center, and the board needs to split resources between risk management and profit centers. In general, the more resources are allocated to risk management the better risk is measured and managed, but at the expense of lower profitability.

Since our interest is in understanding the interplay between internal and external risk management, we model the bank as a principal-agent relationship between two separate entities, the board and the risk manager. The board incurs expenses by employing a risk manager and makes two related decisions:

\footnotetext{
${ }^{4}$ European Central Bank (2001, p. 69) says with so many words: "Banks with a higher-risk portfolio, by contrast, might stick to the standardsed approach".
} 
What resources to allocate to the risk management function and the degree of delegation to the risk manager. The risk manager in turn decides based on his compensation contract how much effort to put into actually managing risk. The actual effort chosen depends on both the actual resources allocated as well as the level of monitoring by the board, i.e., how much of the risk management function is delegated to the risk manager. In addition, the board is itself subjected to supervision. We chose to not cast the supervisor-board relationship in a principal agent setting for two reasons. First to maintain tractability and obtain closed form solutions. Second, the objective function of the regulators is not clearly defined. While this would be an interesting topic for future research, we follow the observed regulatory drive for containing risk exposures in banks, by exogenously varying the allowable degree of risk taking.

\subsection{The Basic Model}

Our basic setting is a standard principal-agent model with the following time line. First, the board of directors, or board, $b$, of a bank (principal), maximizes its expected utility, $E U_{b}$, by making an one time employment offer to a risk manager, $m$, (agent). The manager by rejecting the offer earns nothing. Consequently, her expected utility, $E U_{m}$, derived from working must always be non-negative. Alternatively, by accepting the offer, the manager selects an effort, incurs personal disutility, and manages bank risk. Finally, the board observes the outcome, and pays the manager the agreed-upon compensation. There is no room for renegotiation. The board has all the bargaining power and, in equilibrium, the manager accepts the offer and receives the certainty equivalent of zero from the optimal contract.

Most principal-agent settings assume that the agent's effort causes a first order stochastic dominating shift in the distribution of the performance measure, see, among others, Holmstrom (1979) and Holmstrom and Milgrom (1987). Recent models allow the agent to take an action that causes instead a second order stochastic dominating shift, see e.g. Hughes (1982), Sung (1995), or Demski and Dye (1999). We choose the latter modelling approach. We note that this approach implies a separation between risk and return choices. Clearly this would hold if the hedging instruments available to the risk manager are priced fairly. More generally, Sung (1995) provides sufficient conditions ${ }^{5}$ under which our results generalize. Our focus is on

\footnotetext{
${ }^{5}$ The disutility of efforts associated with risk and return are assumed to be additively separable.
} 
the trade-off between the cost of risk management and the risk reduction achieved by risk monitoring, taking as given that some risk is unavoidable for a given expected return level.

The manager chooses an effort level, $a$, incurring cost of effort $c$ measured in pecuniary terms. The bank earns profits $Z$, with the following distribution:

$$
Z \sim N\left(u, \sigma^{2}(a)\right)
$$

To ensure a non-trivial solution and avoid wealth effects, we assume that both the board and the manager have negative exponential utility function with constant absolute risk aversion coefficients $\alpha$ and $\beta$, respectively. Further the contract offered to the agent, $s(Z)$, is assumed to be linear, that is, $s(Z)=s_{0}+s_{1} Z$.

In a single period principal-agent model, the linear contract would not be optimal because a sequence of bang-bang contracts approximates the first best solution arbitrarily well, (see Mirrlees, 1999). However, we follow Holmstrom and Milgrom (1987) in considering our model a simplified representation of the continuous choice of effort. Under this assumption, Sung (1995) demonstrates that the optimal second best solution can be implemented using linear contract when the manager controls the variance of the performance measure. As alternative rationales for restricting attention to linear contracts, Diamond (1998) shows asymptotic optimality, while Palomino and Prat (1998) solve a binomial risk management problem under risk neutrality and limited liability, so that payoff is convex. Finally one could argue that linear contracts are closer approximations of observed compensation contracts. To maintain tractability we abstract from limited liability issues. While this is an important issue for understanding attitudes towards risk taking by banks, it is less relevant for the choice between different risk systems, and hence we opt for the simpler specification to get the main message across.

The board offers the contract parameters $s_{0}$ and $s_{1}$ to maximize its utility. Conditional on the choice of these parameters, we can analyze the behavior of the risk manger. The manager's utility is

$$
E U_{m}=-\exp \left(-\alpha \mathrm{E}[s(Z) \mid a]+\alpha c(a)+\frac{\alpha^{2}}{2} \operatorname{VAR}[s(Z) \mid a]\right) .
$$

The first term is the manager's expected compensation, the second term gives the disutility of effort, and the last term is the risk premium. For the contract $s(Z)=s_{0}+s_{1} Z$, we can write

$$
E U_{m}=-\exp \left(-\alpha s_{0}-\alpha s_{1} u+\alpha c(a)+\frac{\alpha^{2}}{2} s_{1}^{2} \sigma^{2}\right) .
$$


Since both board and manager have constant absolute risk aversion and the random variables are normally distributed for any given effort level, we can conveniently transform the manager's expected utility to certainty equivalents:

$$
C E U_{m}=-\alpha^{-1} \ln \left(-E U_{m}\right)=s_{0}+s_{1} u-c(a)-\frac{\alpha}{2} s_{1}^{2} \sigma^{2} .
$$

We follow Holmstrom and Milgrom (1987) in assuming that the manager's personal cost of effort is linear in effort, i.e., $c=k a$. Moreover, we suppose that a unit of effort $a$ lowers the risk through the following production function for risk control

$$
\sigma^{2}(a)=\frac{\Sigma}{\tau+a},
$$

where $\Sigma$ and $\tau$ are given positive parameters. The risk control function features a decreasing marginal return on effort. Thus, for any contract characterized by the pair $\left(s_{0}, s_{1}\right)$ the manager's certainty equivalent utility is

$$
C E U_{m}=s_{0}+s_{1} u-k a-\frac{\alpha}{2} s_{1}^{2} \frac{\Sigma}{\tau+a} .
$$

Similarly, after incorporation of the payment to the manger the board receives

$$
Z-s(Z)=\left(1-s_{1}\right) Z-s_{0} .
$$

Thus expected utility of the board is

$$
\begin{aligned}
E U_{b} & =\exp \left(-\beta \mathrm{E}\left[Z-s(Z) \mid s_{0}, s_{1}\right]+\frac{\beta^{2}}{2} \operatorname{VAR}\left[Z-s(Z) \mid s_{0}, s_{1}\right]\right) \\
& =\exp \left(-\beta\left(1-s_{1}\right) u+\beta s_{0}+\frac{\beta^{2}}{2}\left(1-s_{1}\right)^{2} \sigma^{2}\right)
\end{aligned}
$$

and the certainty equivalent of the board's utility function is

$$
C E U_{b}=\left(1-s_{1}\right) u-s_{0}-\frac{\beta}{2}\left(1-s_{1}\right)^{2} \sigma^{2}
$$

\subsection{Supervision}

Our main interest is in understanding the impact that regulatory supervision has on internal risk modelling within a financial institution. Therefore one would ideally model regulatory preferences in addition to the principal's and agent's preferences discussed above. Unfortunately, regulatory preferences are not well understood, with the most cited rational for regulation being "lowering systemic risk". That leaves one with the question of how to define 
systemic risk, but no single definition of systemic risk is available. Moreover, a translation from systemic risk tolerance to the risk tolerance by the regulator imposed on individual banks as a consequence of its systemic risk tolerance is not available. Therefore, in the current paper we take a positive approach and simply investigate different risk levels permitted by the regulator and its consequences for the bank, without entering into the objectives of the regulators and the efficiency of the current Basel-II proposal on the table.

The board of directors contracts the risk manager to control overall risk taking at a given level of expected return. The manager will have to be compensated for this, and in general needs more compensation for a higher activity level. The regulator desires to contain overall risk taking in the financial sector, and therefore imposes risk constraints on the bank. We treat these regulatory risk constraints as exogenous to the decision-making process. These risk constraints are costly to the bank, e.g., the bank might be at a competitive disadvantage under regulation, or the bank might have to be at a lower risk-return profile than desired.

\section{Risk Management}

We consider two alternative risk management systems, one with a high degree of delegation of responsibilities to the risk manager, and other with a low degree of delegation. We label the first system direct risk monitoring and the second system indirect risk monitoring. When risk monitoring is direct, the Board observes all decisions made by risk manager, while indirect monitoring implies that the Board only observes outcomes, i.e., earnings. The direct system implies first best outcomes while the indirect regime results in second best outcomes.

Currently, financial intermediaries can choose between calculating their market risk in one of two ways. Either they adopt the Basel standardized approach, or they rely on an internal model subject to supervisory approval. Furthermore, the BIS is proposing that credit, liquidity, and operational risk also be regulated by either of the two methods. Typically, the resulting regulatory capital requirements implied by the two methods of calculation do differ and hence the institution may act strategically in choosing its risk management system. This is the central issue of the paper.

There are two possible interpretations of the above scenarios. First, the indirect risk monitoring system may represent the standardized approach, while the direct risk monitoring system may represents the IRB system. Alter- 
natively, the two systems represent different levels of sophistication under the IRB approach. At the end of the paper we will relax the stark contrast between the two systems and allow for a sliding scale of sophistication to justify the observed heterogeneity of banks' risk management systems.

The regulator can either choose not to regulate, or to regulate within the context of each risk management system. In particular, the regulator has the same information as the board, and can influence the risk management system. This results in four different cases:

Indirect Risk Monitoring The risk manager's decision is unobservable to the board of directors and is non-contractible, but the earnings are observable and contractible.

Case A Second best: There is no external risk supervision.

Case B Indirect supervision: The regulator monitors risk taking indirectly through earnings announcements, and possibly influences the risk management process.

Direct or Continuous Risk Monitoring The board of directors implements a costly risk system that reports on a continuous basis.

Case C Costly first best: There is no external risk supervision.

Case D Direct regulation: The regulator directly monitors the risk management process, and possibly influences it.

These four different cases are discussed in turn.

\subsection{Indirect Risk Monitoring without Regulation}

The most common form of risk management within a financial institution is where the management of the bank, usually the risk committee, specifies allowable risk and dedicates the task of actually measuring and managing risk to a risk manager. The dilemma facing the board is that it is unable to observe how well the risk management does his job except in extreme circumstances. As a result, the board only indirectly observes the risk managers decisions. Even if the risk manager reports VaR numbers to the board, these VaR numbers are determined by a model created by the risk manager, and as a result do not represent the actual riskiness of the financial institution but instead a subjective risk forecast from the risk manager. 
We capture this in a stylized way by assuming that the manager's risk management decision is unobservable to the board and hence is non-contractible. This gives rise to a second best solution. As was explained above, the risk manager solves the following problem:

$$
\max _{a} C E U_{m}=s_{0}+s_{1} u-k a-\frac{\alpha}{2} s_{1}^{2} \frac{\Sigma}{\tau+a} .
$$

From the first order conditions, we get $a=-\tau+s_{1} \sqrt{\alpha \Sigma / 2 k}$, and after substitution into $C E U_{m}$ :

$$
C E U_{m}=s_{0}+s_{1} u+\tau k-s_{1} \sqrt{2 k \alpha \Sigma} .
$$

The volatility level chosen by the manager is

$$
\sigma^{2}(a)=\frac{\sqrt{2 k \Sigma}}{\sqrt{\alpha}} \frac{1}{s_{1}}
$$

The board chooses the contract parameters. Note that although the reward is based on the random return $Z$, control is on the variance of $Z$ which is hidden from the board, who then chooses the contract parameters $s_{0}$ and $s_{1}$ such that the manager has a weak incentive to participate, i.e. $E U_{m}=-1$ or $C E U_{m}=0$. From (2) this gives

$$
-s_{0}=s_{1} u+\tau k-s_{1} \sqrt{2 k \alpha \Sigma} .
$$

Substituting the $C E U_{b}$ from the previous section, we obtain

$$
C E U_{b}=u+\tau k-s_{1} \sqrt{2 k \alpha \Sigma}-\frac{\beta}{2}\left(1-s_{1}\right)^{2} \frac{\sqrt{2 k \Sigma}}{\sqrt{\alpha}} \frac{1}{s_{1}} .
$$

Maximize $C E U_{b}$ with respect to $s_{1}$ to get:

$$
s_{1}^{\text {second best }}=\sqrt{\frac{\beta}{2 \alpha+\beta}} .
$$

From (4) it follows that

$$
s_{0}^{\text {second best }}=-u \sqrt{\frac{\beta}{2 \alpha+\beta}}-\tau k+\sqrt{\frac{2 k \alpha \beta \Sigma}{2 \alpha+\beta}} .
$$

Therefore the board's utility is:

$$
C E U_{b}^{\text {second best }}=u+\tau k-\frac{2 \alpha+\beta-\sqrt{\beta(2 \alpha+\beta)}}{\sqrt{\alpha(2 \alpha+\beta)}} \sqrt{2 k \beta \Sigma} .
$$


From the manager's problem we have $a=-\tau+\sqrt{\alpha \Sigma / 2 k} s_{1}$. With the solution for $s_{1}$, this gives the second best solution for effort and volatility:

$$
\begin{aligned}
a^{\text {second best }} & =-\tau+\sqrt{\frac{\alpha \Sigma}{2 k} \sqrt{\frac{\beta}{2 \alpha+\beta}}}, \\
\sigma_{\text {second best }}^{2} & =\sqrt{\frac{2 k \Sigma(2 \alpha+\beta)}{\alpha \beta}} .
\end{aligned}
$$

Remark 1 We implicitly assume that the parameters $\tau, \alpha, \Sigma, \beta, k$ are such that $a>0$. Similarly, we assume that the parameters $\tau, \alpha, \Sigma, \beta, k, u$ are such that $C E U_{b}^{\text {second best }}>0$. Note that we have enough degrees of freedom for this to hold (e.g., choose $u$ sufficiently large and $\tau$ sufficiently small for any given positive values of the remaining parameters). Moreover, we require a small $\tau$ to ensure that the board be interested in hiring a risk manager, that is, $C E U_{b}^{\text {second best }}>u-\beta \Sigma / 2 \tau$.

Remark 2 While not directly relevant for the topic of the paper, one might like to make explicit the trade-off faced by the board between risk and return in selecting investment opportunities (the analysis in the paper is carried out under the presumption that the projects have already been selected). In the current setup we assume that the board is faced with running projects with a given level of expected return. A simple way to capture the tradeoff is to make $u$ a sufficiently concave function of $\Sigma$, and to let the board optimize with respect to $\Sigma$ as well. One easily verifies that this leaves the above derivations essentially unaffected, except for the fact that $u$ is now endogenously determined.

\subsection{Indirect Risk Monitoring with Regulation}

The risk manager reports the outcomes of the risk models to the board as well as regulators, and these risk forecasts are used to determine minimum bank capital. As in the previous case, these risk forecasts are merely estimates of the actual riskiness of the financial institution. The regulators do audit the internal risk models, however, for most parts these models represent the subjective decisions made by the risk manager. The regulators supposedly note that the bank's activities create negative externalities that must be corrected by means of risk regulation. An example of this arises when excessive risk-taking, while individually optimal, destabilizes the economy. While supervision can be costly for several reasons, e.g. due to lack of 
competitiveness, foregone earnings, or audit costs as in Merton (1978), supervision may also increase the rents from monopoly power due to increased barriers to entry. We capture the effect of supervision by means of a tax on bank profits. Specifically, we consider a proportional tax on the abnormal bank profits (unexpected), $t$, related to the unexpected part of the variable compensation paid to the risk manager, $s_{1}(Z-u)$, that is, the total tax is $t s_{1}(Z-u)$. When $t>0$, this captures a fundamental aspect of the risk regulation, i.e., their procyclicality. Under such regulation, the bank records higher profits in upswings and more losses in downturns than it would if left unregulated.

The regulatory cost, $t s_{1}(Z-u)$, is transferred between the profit and an accounting reserve ${ }^{6}$. If the regulatory tax is placed in an accounting reserve where the supervisors neither retain part of the accounting reserve nor top it up, the reserve is self financing. The account will be zero on average since $\mathrm{E}\left[t s_{1}(Z-u)\right]=0$. If, however, the government serves as the lender of last resort then it effectively contributes a call option to the accounting reserve.

When the bank earns profit $Z$, it receives $t s_{1}(Z-u)$ from the accounting reserve such that the net return to the board becomes

$$
-s_{0}+\left(1-s_{1}\right) Z+t s_{1}(Z-u) .
$$

Because the utility of the board of directors is of the mean-variance type with risk aversion parameter $\beta$, its utility becomes

$$
C E U_{b}=-s_{0}+\left(1-s_{1}\right) u-\frac{\beta}{2}\left(1-s_{1}+t s_{1}\right)^{2} \sigma^{2} .
$$

From the solution of the managers problem (4) we can substitute out $s_{0}$, and use (3) to rewrite this as

$$
C E U_{b}=u+\tau k-\sqrt{2 k \alpha \Sigma} s_{1}-\frac{\beta}{2}\left(1-(1-t) s_{1}\right)^{2} \frac{\sqrt{2 k \Sigma}}{\sqrt{\alpha}} \frac{1}{s_{1}} .
$$

The board maximizes $C E U_{b}$ with respect to $s_{1}$. From the first order condition, the solution for $s_{1}$ follows

$$
s_{1}^{\text {indirect supervision }}=\sqrt{\frac{\beta}{2 \alpha+(1-t)^{2} \beta}} .
$$

\footnotetext{
${ }^{6}$ This accounting reserve is considered to be part of the capital base, the level of which is directly related to the risk of other balance sheet items. In The Netherlands for example, banks are required to administer such an accounting reserve. This requirement works effectively like a tax on capital since it changes the effective amount of profits distributed to the owners. To the regulators such an account is an instrument for inducing better risk management, as we show below.
} 
By insertion, we get the certainty equivalent utility, $C E U_{b}(t)$. Moreover, volatility becomes

$$
\sigma^{2}=\frac{\sqrt{2 k \Sigma}}{\sqrt{\beta \alpha}} \sqrt{2 \alpha+(1-t)^{2} \beta}
$$

It is easily seen from this latter expression or from (3) that the regulatory provision which minimizes risk taking entails maximizing $s_{1}$, i.e. setting $t=$ 1. The regulatory effect of $t=1$ is seen from (5) to undo, from the perspective of the board, the risk sharing with the manager. From the manager's point of view, the project risk combined with higher variable reward parameter $s_{1}$ increases the incentives for risk reduction.

The risk minimizing solution $t=1$ is independent of both the effort aversion and risk reduction capabilities of the manager, as well as the risk aversion of the board of directors or the manager. This system exposes the board to more volatility in order to induce the appropriate risk reduction. The increase of the board of directors' exposure to compensation risk is optimal for meanvariance preferences. ${ }^{7}$ Note, moreover that with $t=1$ the regulatory measure is procyclical. It has been argued that the Basel-II proposals can have this effect when implemented, see e.g. The European Central Bank (2001, p. 64-68) .

Remark 3 In the previous subsection we discussed a simple way to capture the board's trade-off between risk and return in selecting investment projects by letting the mean return $u$ depend on $\Sigma$. Suppose $u=\Sigma^{\phi}$, where $0<\phi<$ $1 / 2$. Let the board optimize with respect to $\Sigma$ as well as over $s_{1}$. It then follows that $\Sigma(t=0)<\Sigma(t=1)$, but $\sigma^{2}(t=0)>\sigma^{2}(t=1)$. Thus as a result of the regulatory capital requirements the board selects projects with higher risk, but the extra effort in containing the risk by the risk manager following the imposition of the tax more than offsets this effect.

\subsection{Direct Risk Monitoring: No Regulation}

Suppose that the bank is discontent with only monitoring the final output of risk management process. The bank therefore installs a risk management system that reports continuously to the board the level of risk taking. Continuous risk reporting implies that the board controls the manager completely, leaving no room for hidden action, in effect the board runs the bank. This

\footnotetext{
${ }^{7}$ We considered more general regimes. Since, in principle, $s_{0}, s_{1}$, and $Z$ are all observable to the supervisor a proportional provision could be imposed on each item (denoted by $t_{0}, t_{1}$, and $\left.t_{2}\right)$. The results of these different schemes are all qualitatively similar.
} 
risk reporting system comes at a fixed cost, $F$, and measures the variance, which is a sufficient statistic for VaR given the distributional assumptions. The VaR system thus reveals the volatility to both parties.

The board can then choose the contract parameters $\left(s_{0}, s_{1}\right)$ to obtain a 'first best' solution where the reward could be based directly on the observed volatility. Hence, the board pays the manager such that she is indifferent between working or not working, i.e., $E U_{m}=-1$ or $C E U_{m}=0$ :

$$
-s_{0}=s_{1} u-k a-\frac{\alpha}{2} s_{1}^{2} \frac{\Sigma}{\tau+a} .
$$

Substituting this into the boards' utility function yields certainty equivalent of

$$
C E U_{b}=u-k a-\frac{\alpha}{2} s_{1}^{2} \frac{\Sigma}{\tau+a}-F-\frac{\beta}{2}\left(1-s_{1}\right)^{2} \frac{\Sigma}{\tau+a} .
$$

The board maximizes $E U_{b}$ with respect to $s_{1}$ and $a$ resulting in

$$
s_{1}^{\text {costly first best }}=\frac{\beta}{\alpha+\beta} .
$$

Indeed, this is the optimal risk sharing in agencies in the absence of moral hazard, see Wilson (1968). Since this condition does not depend on managerial effort $a$, we can substitute into $C E U_{b}$ to obtain the following simplification:

$$
C E U_{b}=u-k a-\frac{1}{2} \frac{\alpha \beta}{\alpha+\beta} \frac{\Sigma}{\tau+a}-F .
$$

It follows from maximizing $C E U_{b}$ with respect to choice of $a$ that the costly first best solutions are

$$
\begin{aligned}
a^{\text {costly first best }} & =-\tau+\sqrt{\frac{\alpha \beta \Sigma}{2 k(\alpha+\beta)}}, \\
\sigma_{\text {costly first best }}^{2} & =\sqrt{\frac{2 k \Sigma(\alpha+\beta)}{\alpha \beta}},
\end{aligned}
$$

resulting in the boards' utility

$$
C E U_{b}^{\text {costly first best }}=u+\tau k-F-\sqrt{\frac{2 k \alpha \beta \Sigma}{\alpha+\beta}} .
$$




\subsection{Direct Risk Monitoring with Regulation}

Since the project payoffs (1) are normally distributed, the variance $\sigma^{2}(a)$ is a sufficient statistic for VaR. Consequently, exogenous regulation needs only stipulate an upper bound $\Omega$ on the admissible variance:

$$
\sigma^{2} \leq \Omega
$$

In the case of contractible risk management, the regulators as well as the board of directors observe the VaR. This enables the regulator to directly supervise risk taking by enforcing the restriction (6). If the constraint (6) is set such that it is binding, i.e. $\Sigma /(\tau+a)=\Omega$ it implies that effort necessarily equals

$$
a^{\text {directly regulated }}=\frac{\Sigma-\tau \Omega}{\Omega} .
$$

The certainty equivalent of the expected utility of the manager becomes

$$
C E U_{m}=s_{0}+s_{1} u-\frac{k \Sigma}{\Omega}+k \tau-\frac{\alpha}{2} s_{1}^{2} \Omega .
$$

From the manager participation constraint we get

$$
s_{0}=\frac{k \Sigma}{\Omega}-k \tau-s_{1} u+\frac{\alpha}{2} s_{1}^{2} \Omega
$$

The boards' utility then reads

$$
C E U_{b}=u+k \tau-\frac{k \Sigma}{\Omega}-\frac{\alpha}{2} s_{1}^{2} \Omega-\frac{\beta}{2}\left(1-s_{1}\right)^{2} \Omega-F .
$$

Maximizing $C E U_{b}$ yields the optimal slope of the manager's compensation

$$
s_{1}^{\text {directly regulated }}=\frac{\beta}{\alpha+\beta},
$$

just as in the case of contractible risk management. Hence, the optimal fixed part of the salary is

$$
s_{0}^{\text {directly regulated }}=\frac{k \Sigma}{\Omega}-k \tau-\frac{\beta}{\alpha+\beta} u+\frac{\alpha}{2} \Omega\left(\frac{\beta}{\alpha+\beta}\right)^{2}
$$

and the boards' utility:

$$
C E U_{b}^{\text {directly regulated }}=u+\tau k-\frac{k \Sigma}{\Omega}-\frac{\alpha \beta \Omega}{2(\alpha+\beta)}-F
$$

Under direct regulation, a continuous VaR reporting system also reports risk to the supervisors, who in effect free ride on the internal VaR measures. This might, however, not be in the interest of the bank if the resulting restriction on risk taking constitutes a competitive disadvantage. 


\subsection{Evaluation}

In order to compare the four cases, consider the outcomes where the risk aversion is equal, i.e. $\alpha=\beta$, and the capital adequacy tax minimizes risk taking, i.e. $t=1$ and $\Omega$ in (6) is set binding:

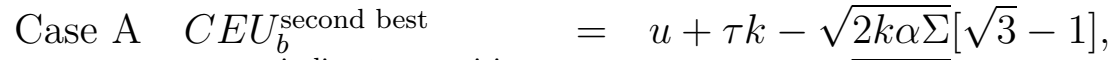

Case B $C E U_{b}^{\text {indirect supervision }}=u+\tau k-\sqrt{2 k \alpha \Sigma} \sqrt{2}$,

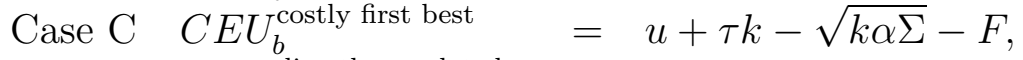

Case D $C E U_{b}^{\text {directly regulated }}=u+\tau k-\frac{k \Sigma}{\Omega}-\frac{\alpha \Omega}{4}-F$.

In this situation the bank prefers no regulation: ${ }^{8}$

Proposition 1 Since $C E U_{b}^{\text {indirect supervision }}<C E U_{b}^{\text {second best }}$, and $C E U_{b}^{\text {directly regulated }}<C E U_{b}^{\text {costly first best }}$, the board prefers no regulations.

Proof. Direct since $\sqrt{3}-1<\sqrt{2}$, and $\sqrt{k \alpha \Sigma}<\frac{k \Sigma}{\Omega}+\frac{\alpha \Omega}{4}$, if the constraint (6) is binding.

Consider the unregulated industry. Even in the absence of regulation, the industry might self-enforce a comprehensive VaR reporting system.

Proposition 2 Suppose there is no external supervision. If $F<\sqrt{2 k \alpha \Sigma}\left[\sqrt{3}-1-\frac{1}{\sqrt{2}}\right]$, the bank will install the continuous risk management system.

Proof. From $C E U_{b}^{\text {costly first best }}=C E U_{b}^{\text {second best }}$, we obtain $F=\sqrt{2 k \alpha \Sigma}\left[\sqrt{3}-1-\frac{1}{\sqrt{2}}\right]$.

Therefore, if the cost of the VaR reporting system $F$ is moderate, the board of directors will opt for the continuous risk management system. ${ }^{9}$

The decision whether to install the continuous risk measurement system, depends on the regulatory environment. In the quote in the introduction, FRB Governor L. H. Meyer hinted that regulators may in the future incorporate the internal risk management process more closely into the supervisory process. However, this might not be in the interest of the board of directors if the resulting restriction on risk taking constitutes a competitive disadvantage. We compare two cases of regulation.

\footnotetext{
${ }^{8}$ Regulation may also work as an entry deterrence, and hence may actually be liked by the management for this reason.

${ }^{9}$ Note that, absent competition in the market for risk management systems, it is conceivable that the dominant risk management consultant is able to extract all the surplus until $F=\sqrt{2 k \alpha \Sigma}\left[\sqrt{3}-1-\frac{1}{\sqrt{2}}\right]$.
} 
Proposition 3 With regulation where the fixed cost of the continuous risk management system is negligible, i.e. $F=0$ so that in the absence of regulation the VaR system is implemented, the board of directors may nevertheless choose not to install the risk management system in the presence of supervision.

Proof. Consider the regulated case where the supervisor benefits from the presence of the sophisticated risk management system. From the following partial derivatives

$$
\frac{\partial C E U_{b}^{\text {direct regulation }}}{\partial \Omega}=k \Sigma \Omega^{-2}-\alpha / 4
$$

and

$$
\frac{\partial^{2} C E U_{b}^{\text {direct regulation }}}{\partial \Omega^{2}}=-2 k \Sigma \Omega^{-3}<0,
$$

we see that $C E U_{b}^{\text {direct regulation }}$ is concave in the imposed risk level $\Omega$, and attains its maximum at $\Omega=\sigma_{\text {first best }}^{2}=2 \sqrt{k \Sigma / \alpha}$. In that case

$$
C E U_{b}^{\text {direct regulation }}=C E U_{b}^{\text {first best }}=u+\tau k-\sqrt{k \alpha \Sigma}>0 .
$$

Moreover

$$
\lim _{\Omega \rightarrow 0} C E U_{b}^{\text {direct regulation }}=-\infty .
$$

If the board has not installed the continuous VaR reporting system, the supervisors can not directly observe risk taking. Hence they attempt to regulate indirectly via the capital requirements $t s_{1} Z$, and choose the optimal rate $t=1$, therefore

$$
C E U_{b}^{\text {indirect supervision }}=u+\tau k-2 \sqrt{k \alpha \Sigma} .
$$

Since $u+\tau k-2 \sqrt{k \alpha \Sigma}<u+\tau k-\sqrt{k \alpha \Sigma}$, but $\tau k-2 \sqrt{k \alpha \Sigma}>-\infty$, we can clearly find cases where $C E U_{b}^{\text {indirect supervision }}<C E U_{b}^{\text {direct regulation }}$, but also values of $\Omega$ for which $C E U_{b}^{\text {indirect supervision }}>C E U_{b}^{\text {direct regulation }} .{ }^{10}$

From these results we see that the bank's optimal risk monitoring intensity depends not simply on market conditions and bargaining power with the risk manager, but also on the actions of the supervisory agencies. If the bank perceives the cost of regulation to be too high, it may opt for a lower quality risk management system, since that can lower regulatory cost. As the quote by Governor Meyer indicates, regulators are aware of this. Presently,

\footnotetext{
${ }^{10}$ Note that if the fixed costs $F$ are non-zero, this conclusion is only reinforced.
} 
anecdotal evidence indicates that some banks employ dual risk management systems, one for external and another for internal purposes. If the supervisory authorities then demand access to the internal control system, banks might find yet another way to avoid disclosing too much information about their risk taking activities.

We finally argue that the modelling approach taken above is quite general and does not hinge on the stark differences between the two alternative risk management systems. We chose a specific parameterization of the relation between risk management activities and the reduction in variance. We could have allowed for a distinction between actual bank profits and the observable and contractible profitability measure based on which the risk manager is compensated. The measurement error in the contracting relationship would tend to exacerbate the difference between the indirect and direct risk monitoring. Nonetheless, we can show that the qualitative results remain, but giving a continuous variation in risk management quality varying with the cost structure of a particular bank. This is shown in the Appendix.

Alternatively, we could have allowed a stochastic variance for any given level of effort. If for any given realized variance, firm profits are normally distributed, linear contracts can still be employed for the reasons outlined above, see references in Sung (1995). Under indirect risk management, the main difference is that the risk manager must be compensated for the additional risk associated with uncertain variance. This is intuitive because of the induced fatter tails in the distribution. Under direct risk management, however, the observed, realized variance no longer perfectly reveals the risk manager's action and could overstate or understate the intended risk exposure of the bank.

\section{Conclusion}

Regulation of the financial industry is primarily motivated by fear of a systemic crisis. Bank regulation takes place in an environment of rapid technological advancements and deregulation. This makes preventing systemic crises by regulatory means increasingly difficult. Indeed, as the present regulatory structure appears to have been created without much regard to financial-economic developments, its suitability for its task remains in doubt.

A rapidly increasing body of literature on financial regulation and financial crises is emerging, and hence our understanding of how to optimally regulate the finance sector has grown. To the best of our knowledge the selection of a particular risk management system by the board has received little attention. 
We consider the financial-economic implications of externally imposed risk constraints in an imperfect market setting: a principal-agent relationship between a regulator, a bank's board of directors, and a risk manager. We model explicitly the strategic choice between alternative risk management systems and the influence of regulation on this choice. The regulators explicitly allow for this by giving banks the choice between two quite different approaches towards determining the regulatory capital; moreover, within the IRB approach there are several degrees of freedom for the institution as to how to proceed with the risk measurement. Typically, the resulting regulatory capital requirements implied by the two methods of calculation do differ and hence the institution may act strategically in choosing its risk management system. This is the central issue of the paper. Thus, the presence of external regulation has real effects, like the noted procyclicality.

There is potential for a decrease in the banks' market value coupled with an increase in total risk as a consequence of regulatory actions. As a result, improperly crafted regulations can have serious unintended consequences, and a bad regulatory design may be worse than no regulation. Therefore, it is important to subject regulatory designs to rigorous financial-economic analysis prior to implementation. In particular, we give conditions under which the bank when left to itself chooses a better risk management system than when it is supervised.

Lastly, an interesting issue is also whether the capital determined by the IRB is actually binding. Most academic literature seems to assume that financial institutions minimize capital, e.g., that in the case of market risk capital equals three times VaR plus a constant. This is however an incorrect assumption. Most banks are considerably overcapitalized, and while regulatory capital might represent the minimum allowable capital, it is a point seldom reached. The question of why banks are overcapitalized is interesting. While the banks give multiple explanations for this, one cannot escape the feeling that bank over capitalization is one manifestation of information asymmetry. If a bank's minimum allowable capital is $8 \%$ but it's actual capital is $13 \%$, as often is the case, the bank must a very good reason for this. Perhaps the reason is that the bank really is riskier than the regulatory model implies. After all, if the regulatory risk model is accurate there is no reason to be significantly overcapitalized. In other words, the bank realizes that the regulatory VaR model is unreliable, and uses a different model for internal capital determination. We have captured this information asymmetry in a stylist way in our model. 


\section{Appendix}

Suppose the risk manager can only measure the banks positions with error. This reflects the real world where the bank can only approximate its holdings in real-time due to administrative hurdles. Let $Z$ represent as before the real return, and let $r$ be a noisy signal with precision $\gamma$. The measured return is then $\hat{Z}$ where

$$
\hat{Z}=Z+r
$$

The distribution of the signal is

$$
r \sim \operatorname{iid} N\left(0, \frac{1}{\gamma}\right)
$$

As a result, the perceived production function for volatility is therefore

$$
\begin{aligned}
\hat{\sigma}^{2}(a) & =\frac{\Sigma}{\tau+a}+\frac{1}{\gamma} \\
& =\sigma^{2}+\frac{1}{\gamma}, \gamma \geq 0
\end{aligned}
$$

where $\sigma$ is the real volatility while $\hat{\sigma}$ is the perceived volatility, with $\hat{\sigma} \geq \sigma$, where $\gamma$ is known to the agent, and is determined by the principal. The cost of the risk model for the principal is assumed to be proportional to the signal precision, i.e., $\gamma F$. In this case it is prohibitively expensive for the principal to exactly measure risk, and infeasible not to allocate any resources to risk management.

The board of directors pay the manager just enough to be willing to work, that is, $C E U_{m}=0$ :

$$
-s_{0}=s_{1} u-k a-\frac{\alpha}{2} s_{1}^{2}\left(\frac{\Sigma}{\tau+a}+\frac{1}{\gamma}\right) .
$$

Since both the principle and agent perceive volatility and hence risk as the same, as before from the manager's problem

$$
\hat{\sigma}^{2}(a)=\frac{\sqrt{2 k \Sigma}}{\sqrt{\alpha}} \frac{1}{s_{1}} .
$$

Use this to obtain the board of directors' objective

$C E U_{b}=u+\tau k-s_{1} \sqrt{2 k \alpha \Sigma}-\gamma F-\frac{\beta}{2}\left(1-s_{1}\right)^{2} \frac{\sqrt{2 k \Sigma}}{\sqrt{\alpha}} \frac{1}{s_{1}}-\frac{\beta}{2} \frac{1}{\gamma} s_{1}{ }^{2}-\frac{\alpha}{2} \frac{1}{\gamma} s_{1}{ }^{2}$. 
Maximize $C E U_{b}$ with respect $\left(s_{1}, \gamma\right)$. The solution from the first order necessary conditions is

$$
s_{1}=\sqrt{\frac{\beta}{\beta+2 \alpha[1+\sqrt{(\alpha+\beta) F / k \alpha \Sigma}]}}
$$

and

$$
\gamma=\sqrt{\frac{\beta(\alpha+\beta) / 2}{\beta F+2 \alpha[1+\sqrt{(\alpha+\beta) / k \alpha \Sigma}] F^{3 / 2}}} .
$$

It follows that $d(1 / \gamma) / d F>0$. 


\section{References}

Basel Committee on Banking Supervision (1996). Overview of the amandment to the capital accord to incorporate market risk.

Crockett, A. (2000). Marrying the micro- and macro-prudential dimensions of financial stability. Bank for International Settlements ; http://www. bis.org/review/rr000921b.pdf.

De Bandt, O. and Hartmann, P. (2000). Systemic risk: a survey. Discussion paper series, no. 2634, CEPR.

Demski, J. S. and Dye, R. (1999). Risk return and moral hazard. Journal of Accounting Research, 37:27-55.

Diamond, P. (1998). Managerial incentives: On the near linearity of optimal contracts. Journal of Political Economy, 106 (5):931-957.

European Central Bank (2001). The new capital adequacy regime - the ECB perspective. Monthly Bulletin, May, p. 69.

Holmstrom, B. (1979). Moral hazard and observability. Bell Journal of Economics, 10:74-91.

Holmstrom, B. and Milgrom, P. (1987). Aggregation and linearity in the provision of intertemporal incentives. Econometrica, 55:303-328.

Hughes, J. (1982). Agency theory and stochastic dominance. Journal of Financial and Quantitative Analysis, 17:341-361.

Merton, R. C. (1978). On the cost of deposit insurance when there are surveillance costs. Journal of Business, 51:439452.

Meyer, L. H. (2000). The challenges of global financial institution supervision. Remarks by Governor Laurence H. Meyer.

Mirrlees, J. (1999). The theory of moral hazard and unobservable behavior, part i. Review of Economic Studies, 66 (1):3-21.

Palomino, F. and Prat, A. (1998). Risk taking and optimal contracts for money managers. presented at ESEM 98.

Sung, J. (1995). Linearity with project selection and controllable diffusion rate in continuous time principal agent problems. RAND Journal of Economics, 26 (4):720-743.

Wilson, R. (1968). The theory of syndicates. Econometrica, 36:119-131. 